\title{
O Centro de Educação a Distância da UNB no contexto da internacionalização: integração de ações educativas inovadoras com uso de tecnologias digitais
}

\author{
UNB'S Distance Education Center in the context of internationalization: integration of innovative \\ educational actions with the use of digital technologies
}

\section{Le Centre D'éducation à Distance de l'UNB dans le contexte de l'internationalisation: intégration d'actions éducatives innovantes avec l'utilisation des technologies numériques}

\author{
Marcello Ferreira ${ }^{1}$ \\ Instituto de Física/UnB
}

Teresinha de Jesus A. M. Nogueira ${ }^{2}$

$\mathrm{UFPI} / \mathrm{CEAD} / \mathrm{UnB}$

\author{
Danielle Xabregas Pamplona Nogueira ${ }^{3}$ \\ Departamento de Planejamento e Administração/UnB
}

Helena Célia de Souza Sacerdote ${ }^{4}$ $\mathrm{CEAD} / \mathrm{UnB}$

Resumo: Este estudo trata das ações do Centro de Educação a Distância (CEAD) da Universidade de Brasília (UnB) no cenário da internacionalização educacional. Considera a internacionalização como processo de integrar uma dimensão internacional e intercultural na educação superior, por meio de interação e práticas colaborativas. Com o objetivo de analisar as ações do CEAD voltadas para a internacionalização, com foco na extensão, a pesquisa exploratória, após análise documental, revelou que esse Centro contribui com ações inovadoras, por meio dos programas Universidade Aberta do Brasil e Aprendizagem para o $3^{\circ}$ Milênio (A3M), com o destaque para o convênio com a Universidade Aberta de Portugal (UAb), e se materializa, primordialmente, em ações de divulgação.

Palavras-chave: Internacionalização. Universidade de Brasília. Educação a Distância. Tecnologias digitais.

\footnotetext{
${ }^{1}$ Professor no Instituto de Física da Universidade de Brasília (UnB). Doutor em Educação em Ciências pela UFRGS, mestre em Ensino de Física e licenciado em Física pela UnB. Atualmente, é vice-coordenador do Programa de Pós-Graduação em Ensino de Física, coordenador da cooperação internacional UAB-UnB/UAb e Coordenador-Geral da UAB na UnB. E-mail: marcellof@,unb.br; Lattes: http://lattes.cnpq.br/3108824986425884; ORCID: https://orcid.org/0000-0003-4945-3169.

2 Professora da Faculdade de Educação da Universidade Federal do Piauí (UFPI). Mestra e doutora em Educação pela Universidade Federal do Piauí (UFPI), com doutorado Sanduíche no Instituto de Educação da Universidade de Lisboa (IEUL). E-mail: teresinhanogueira@unb.br; Lattes: http://lattes.cnpq.br/1664245311677759; ORCID: https://orcid.org/0000-0002-4217-4928.

3 Professora da Faculdade de Educação da UnB, atuando principalmente nos seguintes temas: políticas públicas, gestão e tecnologias educacionais. Doutora e mestra em Educação pela Universidade de Brasília (UnB). E-mail: $\quad$ daniellen@,unb.br; Lattes: http://lattes.cnpq.br/7455418399257045; ORCID: https://orcid.org/0000-0001-8500-0402.

${ }^{4}$ Doutora e mestra em Ciência da Informação pela Universidade de Brasília (UnB), com especialização em Letramento Informacional (UFG), Design Instrucional (UNIFEI) e Educação a Distância (SENAC/DF). Email: helenasacerdote@unb.br; Lattes: http://lattes.cnpq.br/6300654854015438; ORCID: https://orcid.org/0000-0003-3987-0540.
} 
Resume: This study deals with the actions of the Distance Education Center (CEAD) of the University of Brasília (UnB) in the scenario of educational internationalization. It considers internationalization as a process of integrating an international and intercultural dimension in higher education, through interaction and collaborative practices. In order to analyze CEAD's actions aimed at internationalization, with a focus on extension, exploratory research, after documentary analysis, revealed that this Center contributes to innovative actions, through the Open University of Brazil and Learning for the 3rd Millennium programs (A3M), with emphasis on the agreement with the Open University of Portugal $(\mathrm{UAb})$ and materializes, primarily, in dissemination actions.

Keywords: Internationalization. University of Brasilia. Distance Education. Digital technologies.

Sommaire: Cette étude porte sur les actions du Centre d'enseignement à distance (CEAD) de l'Université de Brasilia (UnB) dans le scénario de l'internationalisation de l'éducation. Il considère l'internationalisation comme un processus d'intégration d'une dimension internationale et interculturelle dans l'enseignement supérieur, à travers des pratiques d'interaction et de collaboration. Afin d'analyser les actions du CEAD visant l'internationalisation, en mettant l'accent sur la vulgarisation, la recherche exploratoire, après analyse documentaire, a révélé que ce Centre contribue à des actions innovantes, à travers l'Open University of Brazil et les programmes Learning for the 3rd Millennium (A3M), en mettant l'accent sur l'accord avec l'Université ouverte du Portugal (UAb) et se matérialise, principalement, dans des actions de diffusion.

Mots-clés: Internationalisation. Université de Brasilia. Enseignement à distance. Technologies numériques.

Recebido em: 04 de março de 2020 Aceito em: 13 de abril de 2020

\section{Introdução}

São muitos os desígnios que influenciam as trajetórias pessoais e acadêmicas voltadas para a aprendizagem dos alunos, principalmente no que diz respeito às mudanças como via de acesso ao conhecimento na sociedade da informação. Essas novas trajetórias nos levam à oportunidade de se discutir como esses processos de transformações têm repercutido na ação pedagógica das universidades, visando ao ensino e à aprendizagem significativos e à promoção de pessoas autônomas e críticas (BOLL, 2013).

Os cenários contemporâneos demonstram que “[...] a dinâmica da sociedade da informação requer educação continuada ao longo da vida, que permita ao indivíduo não apenas acompanhar as mudanças tecnológicas, mas, sobretudo, inovar" (TAKAHASHI, 2000, p. 7). Dada a imposição de tais aprendizagens inovadoras impulsionadas pela sociedade global e interconectada, as ideias de Moran (2017, p. 1) se mostram oportunas quando postulam que se 
devem “ $[\ldots .$.$] incorporar todas as possibilidades que as tecnologias digitais trazem: a$ flexibilidade, o compartilhamento, ver-nos e ouvir-nos com facilidade, desenvolvimento de projetos em grupo e individualmente, visualização do percurso de cada um […]”.

Nesse cenário educacional contemporâneo, é imprescindível que as instituições educativas valorizem o uso de Tecnologias Digitais de Informação e Comunicação (TDIC), mobilizando-as para possibilitar e facilitar o processo de ensino e de aprendizagem de forma ativa e significativa, na perspectiva da cultura digital. Destaca-se o tripé de sustentação da instituição universitária - ensino-pesquisa-extensão - em seu processo de desenvolvimento e atendimento de sua missão:

Ser uma universidade inovadora e inclusiva, comprometida com as finalidades essenciais de ensino, pesquisa e extensão, integradas para a formação de cidadãs e cidadãos éticos e qualificados para o exercício profissional e empenhados na busca de soluções democráticas para questões nacionais e internacionais, por meio de atuação de excelência (UnB, PDI, 2019, p. 40).

Com essa percepção, o Centro de Educação a Distância (CEAD) da Universidade de Brasília $(\mathrm{UnB})^{5}$, a partir de 2017 , apresentou um novo contorno com o desenvolvimento de ações que buscam a inovação educacional. Foram fomentadas as seguintes frentes: programas e projetos que envolvem o Sistema Universidade Aberta do Brasil, com o educação a distância (on-line), o Programa Aprendizagem para o $3^{\circ}$ Milênio (A3M), que integra, presencial e virtualmente, ações de extensão compostas por cursos, minicursos, eventos (seminários, mesa redonda, EDUCATHON), entre outras.

Destaca-se, como objeto da presente discussão, a internacionalização realizada por meio de um Acordo de Cooperação com a Universidade Aberta de Portugal (UAb), que fundamenta-se em várias linhas de desenvolvimento compartilhado de tecnologias, metodologias e ações em educação a distância com suas primeiras ações efetivas estruturadas na divulgação em plataformas da UAb, no formato de aula aberta, de recursos e metodologias ativas desenvolvidas na UnB no âmbito do Programa A3M.

O Programa A3M, coordenado pelo CEAD, surgiu em 2017 com o intuito de atuar e promover institucionalmente a identificação, a valorização e a promoção de ações educacionais inovadoras (CEAD, 2019). Quanto à internacionalização, trata-se de um acordo entre a UnB, por meio do Centro de Educação a Distância e do Sistema Universidade Aberta do Brasil - UAB, e a UAb, com vistas à cooperação e ao intercâmbio científico, acadêmico, técnico e cultural (BRASIL, 2018). Dessa forma, o CEAD busca acompanhar as evoluções

\footnotetext{
${ }^{5}$ Neste texto, sempre que indicarmos “CEAD”, estaremos tratando do Centro de Educação a Distância (CEAD) da Universidade de Brasília (UnB).
} 
tecnológicas sociais e educativas que envolvem as modalidades educacionais (presencial e a distância), bem como o novo perfil dos estudantes, identificados como "nativos digitais" (FULLAN, 2000), com plena atenção ao Projeto de Desenvolvimento Institucional - PDI (UNB, 2018) e às demandas de uma educação cada vez mais global e sem fronteiras.

Para alcançar essa educação, impõe-se a necessidade de as universidades transformarem suas práticas e processos. Como contribuição, a internacionalização apresenta-se como uma dimensão importante para o desenvolvimento de qualificações internacionais e interculturais. É por meio dela que a universidade se abre a experiências globais e relações externas, permitindo o compartilhamento de experiências educacionais, científicas, tecnológicas e inovadoras.

Com essa compreensão, o desenvolvimento deste estudo parte do seguinte problema: como o CEAD, no cenário organizado pelo projeto de desenvolvimento institucional da UnB, tem contribuído para a efetivação da política de internacionalização da universidade? Tem-se por objetivo geral analisar as ações do CEAD voltadas à internacionalização, no sentido de atender às finalidades essenciais de ensino, pesquisa e extensão, com foco na inovação.

\section{Fundamentação teórica}

Segundo Morosini e Corte (2018), globalização e internacionalização são conceitos que dialoguem historicamente nem que possuem íntima atuação na [re]formulação e [re]configuração das políticas sociais em nível mundial. Desse modo, o fenômeno da globalização transcende a área da educação e apresenta inter-relações com a economia, a cultura, entre outras áreas. Para Sousa (2017), a globalização exerce forte influência sobre o ensino superior, desde a última década, e a internacionalização emergiu como a principal resposta a esse fenômeno. A dimensão internacional vem ganhando destaque nas agendas de instituições e de sistemas de ensino superior em todo o mundo.

Na educação superior a internacionalização equivale, portanto, a um movimento de grande abertura dos países às relações sociais externas visando à ampliação de competências diversas, como, por exemplo, educacionais, científicas e tecnológicas. Concretamente, ela pode se manifestar pelo crescente aumento da movimentação transnacional de pesquisadores, estudantes e professores universitários. O conhecimento mútuo gerado por esse movimento acontece em contextos igualmente diversificados: social, educacional, cultural, político, geográfico, econômico e linguístico, dentre outros (SOUSA, 2017, p. 348).

No âmbito da educação superior, portanto, a internacionalização ocorre por meio de práticas direcionadas à produção, colaboração e difusão do conhecimento. Tais práticas 
visam: à mobilidade no sentido amplo; à transferência de conhecimento entre sistemas educacionais entre nações; as melhorias e mudanças organizacionais e administrativas; à inovação curricular e de desenvolvimento profissional; à excelência no exercício da docência; à excelência na produção e socialização do conhecimento; ao desenvolvimento tecnológico, entre aspectos e elementos subjacentes.

A respeito desses processos, Altbach (2009) define globalização como a realidade moldada por uma economia mundial cada vez mais integrada às TDIC, o surgimento de uma rede internacional de conhecimento, o papel da língua inglesa e outras forças além do controle das instituições acadêmicas. Ao mesmo tempo, reconhece a internacionalização como a variedade de políticas e programas que universidades e governos implementam para responder à globalização, incluindo o envio de estudantes ao exterior, a instalação de campus em outros países ou o envolvimento em algum tipo de parceria interinstitucional.

Assim, Morosini e Corte (2018) evidenciam a repercussão da globalização nos modos de pensar, normatizar, regular e gerir a educação superior, tanto em contex to global quanto local. Para elas, as universidades têm investido em processos de internacionalização, ultrapassando suas fronteiras, tornando-se peça-chave na dinâmica de cooperação e produção entre as nações e seus respectivos mercados. Dito isso, Morosini (2019) define que internacionalização da educação superior é:

Processo de integrar uma dimensão internacional e intercultural na Educação Superior, advindo de interações, sustentadas por redes colaborativas, com blocos socioeconômicos desenvolvidos e com outros que valorem múltiplas culturas, diferenças, locais e tempos, fortalecendo a capacidade cientifica nacional, com o fito de ser irradiador do desenvolvimento sustentável (MOROSINI, 2019 apud MOROSINI, 2017).

Altbach (2009) define que, além dos conceitos gerais de internacionalização e globalização, vários outros termos são usados - como dimensão internacional, educação internacional, programação internacional, cooperação internacional e/ou interinstitucional, parcerias internacionais, educação transfronteiriça, educação sem fronteiras e regionalização. A terminologia variada refere-se à amplitude de experiências nessa área e às abordagens distintivas à internacionalização adotadas por diferentes sistemas e instituições de ensino superior em todo o mundo.

São várias as estratégias de gestão institucional voltadas à internacionalização das Instituições de Ensino Superior. Segundo Morosini (2019), dentre elas, estão:

- $\quad$ escritório internacional voltado para internacionalização; 
- $\quad$ construção compartilhada do conhecimento pela formação de redes regionais continentais e intercontinentais;

- $\quad$ atividades de intercâmbio e participações em eventos internacionais;

- $\quad$ mobilidade acadêmica; e

- construção e difusão de conhecimento via programas de cooperação acadêmica internacional.

Dessas estratégias, avultamos, nesse texto, a cooperação acadêmica internacional. De acordo com Morosini (2019), tal cooperação tem evidenciado envolvimento dos pesquisadores em estudo e construção compartilhada do conhecimento pela formação de redes regionais, continentais e intercontinentais que aproximam centros de ensino e de pesquisa. Esse movimento tem a finalidade de produzir conhecimento científico e tecnológico, colocando as comunidades científicas de diferentes partes do planeta mais próximas e comprometidas com a construção e difusão do conhecimento. Para alcançar esse envolvimento, a autora alerta que "É preciso avançar para que a $\operatorname{IES}^{6}$ adote uma política de internacionalização voltada para elementos de sinergia entre o ensino, a pesquisa e a extensão, reconhecendo as potencialidades do país de origem e dos países parceiros nos processos de cooperação internacional” (MOROSINI, 2019, p. 114).

Altbach (2009) contribui com esta discussão quando apresenta o conceito de “internacionalização em casa”, que consiste em estratégias e abordagens projetadas para introduzir uma dimensão internacional na experiência do campus - por exemplo, incluindo perspectivas globais e comparativas no currículo ou recrutando estudantes, acadêmicos e professores internacionais e alavancando sua presença física nos espaços universitários. Já o conceito de "internacionalização no exterior", por seu turno, exige que uma instituição se projete no mundo, difundindo a sua participação em outros países.

Dessa forma, compreende-se que, ao adotar a estratégia de cooperação internacional, a IES faz sua projeção mundial, colocando em evidência suas atividades de ensino, pesquisa e extensão, ao mesmo tempo que possibilita o intercâmbio de experiências e soluções exitosas com outras instituições. Ademais, extrapola seu contexto local e incorpora em sua cultura práticas globais de formação profissional, de desenvolvimento de competências interculturais, de qualificações internacionais, enfim, de cidadania planetária.

Destarte, Sousa (2017) considera que a internacionalização apresenta novas e empolgantes oportunidades de cooperação, podendo ser uma ferramenta para o aprimoramento da qualidade e para a inserção da inovação em diversos aspectos. No entanto, 
muitas ameaças e desafios significativos devem ser enfrentados em um ambiente de ensino superior global dispendioso, célere e competitivo. Deve-se considerar que tal fenômeno ocorre em um cenário de desigualdade inerente em todo o mundo. Por isso, é necessário entender e aproveitar os benefícios da internacionalização, minimizando os riscos e custos.

Em interpretação alinhada, Altbach (2009) considera que, talvez, a característica mais desconcertante do ensino superior globalizado seja o fato de ele ser, neste tempo, altamente desigual. Nessa conjuntura, cabe salientar que as universidades de elite dos países mais ricos do mundo exercem uma influência desproporcional sobre as definições estratégicas, inclusive temáticas, o desenvolvimento de padrões internacionais de bolsas de estudo, os modelos para administrar instituições e as abordagens de ensino e aprendizagem. Por essa razão, as oportunidades para as instituições mais pobres se envolverem e desenvolverem internacionalmente podem ser limitadas, ao mesmo tempo em que se evidencia o risco da "subordinação" aos modelos externos. Além disso, a educação transfronteiriça, especificamente, apresenta tipos particulares de ameaças, incluindo a perda de identidade cultural, evasão de estudantes para o contexto internacional, qualificações estrangeiras sem reconhecimento local e o não alcance das políticas nacionais de ensino superior.

Diante disso, a internacionalização das universidades se apresenta como um desafio, por um lado, de demandar a abertura da cultura organizacional para influências externas e, por outro, de garantir a íntegra da sua identidade.

\section{Proposta metodológica}

O procedimento metodológico segue o caminho do pensamento e da prática exercida na abordagem da realidade das ações do CEAD. Portanto, é uma pesquisa de abordagem qualitativa, tendo em vista a educação em seu caráter social, dinâmico, provisório e específico em que a "[...] cientificidade tem que ser pensada como uma ideia reguladora de alta abstração e não como sinônimo de modelos e normas” (MINAYO, 2002, p. 12). Com relação aos seus objetivos, trata-se de uma pesquisa exploratória, posto que amplia a capacidade de compreensão da realidade das ações do CEAD, baseada em documentos institucionais e da análise particular de uma relação de internacionalização.

Procedimentalmente, realizou-se a análise documental fundamentada em Bardin (2011, p. 52), que a define como “[ [...] uma operação ou um conjunto de operações visando representar o conteúdo de um documento sob uma forma diferente da original, a fim de facilitar, num estado ulterior, a sua consulta e referenciação”. Também Gil (2017) entende que uma pesquisa documental é caracterizada por documentos internos a uma organização, 
em diversas fontes disponíveis que possam fornecer respostas adequadas para a solução dos problemas propostos, que normalmente são bem delineados.

Neste sentido, para a pesquisa em questão, buscou-se os documentos institucionais, como o PDI, o PPPI e o Plano de Internacionalização da UnB, o Planejamento Estratégico do CEAD, atos, Diário Oficial, site, vídeos, entrevistas, entre outras fontes. Seguindo a trajetória qualitativa da análise documental, procedeu-se à elaboração de categorias, que emergiram das fontes, conduzidos pelo problema e objetivos. Desenvolveu-se a organização do material documental para a categorização, análise e registro dos dados. A categorização, de acordo com Gil (2017), é composta por termos-chave que indicam a semântica principal do conceito tratado, evidenciou as categorias extensão e internacionalização. A articulação teórico-metodológica empregada na resposta à questão enunciada visa auxiliar a compreensão do projeto de internacionalização da UnB, a partir da associação de suas perspectivas documentais e da análise de ações nesse campo.

\section{Resultados}

Os resultados apresentados dispõem, inicialmente, das diretrizes institucionais voltadas à internacionalização. Em seguida, são apresentadas as ações do CEAD no âmbito das políticas de extensão e internacionalização.

\subsection{Ensino/pesquisa/extensão e a internacionalização na UnB}

De forma indissociável, o tripé ensino, pesquisa e extensão é um dos pilares da universidade pública brasileira, conforme previsto na Constituição Cidadã (BRASIL, 1988), em seu artigo 207: “[ [...] as universidades gozam de autonomia didático-científica, administrativa e de gestão financeira e patrimonial, e obedecerão ao princípio de indissociabilidade entre ensino, pesquisa e extensão”. Nesse entendimento, têm-se os significados descritos a seguir.

Ensino é o processo que possibilita a construção do saber, a partir da apropriação do conhecimento historicamente produzido pela humanidade e pela comunidade científica. Decorrente dos novos contextos em que a educação se insere na cultura digital, o ensino passa a ser a mediação desse processo pelo professor, com foco na aprendizagem do aluno, com o apoio de tecnologias digitais. A mediação pedagógica constitui-se em um ensino “[ [...] provocador, contraditor, facilitador, orientador. [...]”, que promove a produção de conhecimento, relacionando-o dialogicamente à realidade do aluno, possibilitando a reconstrução " $[$...] para si, tornando-o seu, dando-lhe um novo sentido” (GASPARIN, 2007, p. 113-114). 
Pesquisa é o processo de materialização do saber, fundamentada em questionamentos, investigação e na produção de novos conhecimentos, particularmente derivados de problemas que emergem da realidade social, na curiosidade e no desejo de investigação e aplicação desses estudos para a promoção de uma sociedade mais justa e humana. Ressalta-se, nesta proposta, a perspectiva de Paulo Freire (1996, p. 32) quando afirma que não há ensino sem pesquisa e pesquisa sem ensino, bem como a interdependência do ensino por meio da curiosidade, indagação - “[ [...] ensino porque busco, porque indaguei, porque indago e me indago. Pesquiso para constatar, constatando, intervenho, intervindo educo e me educo. Pesquiso para conhecer o que ainda não conheço e comunicar ou anunciar a novidade”. As afirmativas desse autor reforçam a articulação entre ensino, pesquisa e extensão, pontuando que esta última se faz por meio da intervenção/aplicação do conhecimento na sociedade, por dispositivos interdependentes e construtivos.

Extensão é o processo educativo, multicultural e científico que objetiva atuação cooperativa, solidária e produtiva nos processos sociais, por meio da identificação de problemas que emergem no cotidiano da realidade que os sujeitos estão inseridos com o fim de atender à responsabilidade social das instituições educativas. Pressupõe-se a extensão como um processo contínuo de retroalimentação entre ensino e pesquisa, articulando conhecimentos acadêmicos e experiências sociais, visando ao desenvolvimento regional e nacional, às relações efetivamente transformadoras, ao diálogo e ao câmbio de saberes em face à superação de desigualdades; e à perspectiva interdisciplinar como forma de superação hegemônica de produção e de difusão dos conhecimentos.

O Planejamento Institucional da UnB (2018-2022) apresenta diretrizes de ensino, pesquisa e extensão, considerando a relação entre excelência acadêmica e atenção às necessidades sociais nos espaços nacionais, regionais e globais que a circunscrevem. O Projeto Pedagógico Institucional (PPI) promove o fortalecimento e a transversalização das ações de internacionalização da UnB, qualificando as atividades de ensino, da pesquisa e da extensão.

No que tange à internacionalização, a efetivação das diretrizes dos referidos documentos ocorre por meio do Plano de Internacionalização da UnB (2018 - 2022). Segundo o documento, historicamente, a internacionalização na UnB decorre da atuação de seus docentes e pesquisadores (bottom-up) e pelo desenvolvimento de políticas institucionais (topdown) para o estabelecimento de diretrizes, prioridades e objetivos. Em sua estrutura, instâncias e órgãos da Administração Superior se corresponsabilizam pela internacionalização da Universidade, sobretudo a Assessoria de Assuntos Internacionais (INT) e os Decanatos de Ensino de Graduação, de Pós-Graduação, de Pesquisa e Inovação, e de Extensão. 
De acordo com o Plano de Internacionalização da UnB (2018, p. 5), o motivo da internacionalização é decorrente das universidades estarem inseridas em constante transformação e crescente globalização, precisando, dessa forma, oportunizar a formação de profissionais preparados para atuar em nível nacional e internacional.

A realização desse propósito implica reestruturações acadêmicas e da gestão universitária, de modo a proporcionar aos estudantes (nacionais e internacionais) mobilidade e trajetórias de formação mais flexíveis, uma formação multi e interdisciplinar para abordar temas complexos, o desenvolvimento do espírito crítico e de uma perspectiva ao mesmo tempo cosmopolita e humanista. Os esforços a ser empreendidos pela instituição nessa direção também visam potencializar a atuação internacional de seu corpo docente e técnico-administrativo, para a integração de atividades acadêmicas em circuitos internacionais, ampliando o sentido social e os efeitos da produção educacional, científica, tecnológica e cultural da UnB.

Na citação, a UnB afirma os motivos gerais da internacionalização e, posteriormente, o Plano apresenta respostas a algumas questões, sendo duas aqui apresentadas:

Por que internacionalizar? Porque a UnB quer formar cidadãos para o mundo, estudiosos das grandes questões mundiais, a fim de colaborar na solução dos importantes problemas da humanidade. Por que queremos a internacionalização? É nossa responsabilidade como educadores preparar estudantes e pesquisadores para participar da sociedade multicultural e ajudálos a se tornar cidadãos globais no futuro (UnB, 2018, p. 7, grifos adicionados).

Como diretriz geral, o Plano propõe que a Universidade avance na mobilidade (docente e discente) e nos acordos bilaterais de cooperação internacional para um novo ciclo de maior e para a efetiva integração a circuitos nacionais e globais de conhecimento. Tal avanço ocorrerá pela participação em redes de universidades e instituições internacionais de pesquisa e pelo incremento da internacionalização em seu próprio ambiente acadêmico.

A política institucional de internacionalização da UnB deve ser transversal às atividades acadêmicas - ensino, pesquisa e extensão - e de gestão da Universidade. Para a consolidação dessa internacionalização em casa, a instituição deve promover a abertura das mentalidades a outros idiomas e culturas, e o estabelecimento de um ambiente de inovação, que estimule a elaboração de respostas para problemas novos, complexos e globais (UnB, 2018, p. 28).

Mormente à extensão, o Plano indica que a internacionalização tem se situado para além da formação acadêmica continuada (discente e docente), chegando à solução de problemas de interesse nacional e internacional, à difusão da ciência, da tecnologia e da cultura, além da promoção do diálogo de saberes (acadêmicos e populares), em ações guiadas por um ideal de solidariedade, sobretudo entre países do hemisfério Sul. De outra forma, o Plano vê a indissociabilidade entre ensino, pesquisa e extensão como um desafio, 
especialmente em ações de alcance internacional. Portanto, ressalta-se a necessidade da existência desse tripé na sustentação das ações universitárias, conjugadamente a uma educação universitária presencial e a distância mais flexível, on-line.

\subsection{Práticas inovadoras e de internacionalização pelo CEAD}

Durante a análise dos documentos do CEAD/UnB, destaca-se a sua fundação em 1989, com a designação de "Centro de Educação Aberta Continuada e a Distância”, na condição de “órgão complementar de ensino, pesquisa e extensão da Universidade de Brasília, com a finalidade de promover educação aberta, continuada e a distância, formal e não formal, em diversos níveis, modalidade e graus, visando à ampliação de oportunidade de acesso ao saber nas várias áreas do conhecimento” (UNB, 1989).

Em sua reorganização institucional, em 2005, o CEAD passa a ter a atual designação, como “Centro de Educação a Distância” (UNB, 2005). Desde então, é responsável por ações de concepção, planejamento e execução de ações em educação a distância na UnB, com foco em suas políticas internas de uso de tecnologias educacionais. Tratava-se de um momento histórico de regulação e implementação massiva da $\mathrm{EaD}$ em âmbito nacional, bem como de grande fomento ao uso mais sistemático e coordenado de tecnologias no ensino, inclusive na modalidade presencial.

A partir de 2017, o CEAD passou a atender às áreas de ensino (graduação e pósgraduação) com ações integradas ao Sistema Universidade Aberta do Brasil (UAB), do Programa Aprendizagem para o $3^{\circ}$ Milênio e dos cursos de extensão em EaD. Essa nova estrutura volta a ter coerência, pelos achados documentais históricos, com a missão originária do Centro. Segundo o Planejamento estratégico (2018-2022):

Com essa reestruturação, o CEAD está centrado na atuação institucional com o papel de incentivar e apoiar a inserção de percentual de carga horária a distância em cursos presenciais, incentivar e apoiar o desenvolvimento de metodologias inovadoras de aprendizagem, manter o suporte às ferramentas de TDIC, já aplicadas ao ensino e aprendizagem, à pesquisa e à extensão, promover capacitações para $\mathrm{o}$ quadro de servidores da Universidade sobre as tecnologias, bem como incentivar e dar suporte à oferta de cursos presenciais e a distância inovadores e sustentáveis (UNB, 2019, p. 9-10, grifos adicionados).

Assim, o CEAD atualmente articula a oferta de cursos de extensão, graduação e de pósgraduação que mobilizam um ensino planejado e sistemático com foco na aprendizagem ativa do aluno. "O CEAD/UnB trabalha, ainda, com ações voltadas ao desenvolvimento de tecnologias e metodologias inovadoras, com o uso de serviços de webconferência, gravação de vídeos e da manutenção do Ambiente Virtual de Aprendizagem da UnB” (UnB/CEAD, 2019, p. 1). Oferece, 
ainda, cursos de formação de professores e tutores, além de módulos autoinstrucionais totalmente on-line, em diversas áreas do conhecimento, em articulação com a UAB/UnB.

O Centro busca cumprir o que está expresso no Planejamento Estratégico (2018-2022), sendo sua missão: "Promover a Educação a Distância na UnB, visando a oferta de ensino de referência social, com ações integradas por metodologias ativas, tecnologias digitais da informação e comunicação e mediadas por práticas pedagógicas inovadoras”. Tal missão é complementada pela visão de "Ser referência em Educação a Distância, com reconhecimento nacional e internacional”, no cumprimento de seus valores que são: “[ $\ldots$.$] foco na Comunidade$ Acadêmica, compromisso com a qualidade, a inovação, a tecnologia e a transparência”.

No novo formato, no contexto das ações institucionais, considera-se a efetiva contribuição do Centro no ensino, na pesquisa e extensão. Particularmente em relação à internacionalização, destacamos o Acordo de cooperação educacional internacional firmado entre a UnB e a Universidade Aberta de Portugal (UAb) - conhecida mundialmente como referência no ensino superior.

O Memorando de Entendimento assinado em Lisboa pelas universidades tem como intuito desenvolver um programa de mútua cooperação e intercâmbio acadêmico, científico e cultural, envolvendo diversas áreas de interesse, com duração prevista de cinco anos. A articulação já se materializou com a integração de pesquisadores das duas instituições, desenvolvimento de materiais on-line e alinhamento de um projeto de mobilidade discente e oferta compartilhada de disciplinas.

O Acordo entre a UnB e a UAb Portugal (BRASIL, 2019) “[ [... inclui programa de intercâmbio acadêmico, científico e cultural e representa mais um campo de aperfeiçoamento na educação a distância da UnB” (CEAD, 2019). Ele possibilita que os docentes e discentes da UnB, façam parte de "[...] um mundo aberto, sem fronteiras, e sua capacidade de compreender e interagir nesse mundo - com mente aberta $[\ldots .$.$] . Porque é importante inserir$ a universidade, com alunos e professores, na discussão e nos desafios que o mundo enfrenta atualmente" (UNB, 2018, p. 7).

O Acordo de Cooperação entre a UnB e a UAb, conforme o Diário Oficial da União publicado dia 20/12/2018 (BRASIL, 2019, p. 43), tem como participantes a Fundação Universidade de Brasília e a UAb, representadas pelos respectivos reitores. O Acordo tem vigência de 05/12/2018 a 05/12/2023, e apresenta por objetivo “[...] regular a forma e as condições pelas quais as partes convenentes se propõem a desenvolver um programa de mútua cooperação e intercâmbio acadêmico, científico e cultural, envolvendo área de interesse mútuo”.

O programa de cooperação envolve: 
a) trocas de informações entre os responsáveis por trabalhos de pesquisa, de equipamentos e material bibliográfico, de experiências e informações pedagógicas, e de recursos de ensino;

b) elaboração de programas de pesquisas;

c) intercâmbio de professores, estudantes, especialistas e técnicos administrativos; E

d) presença recíproca em eventuais debates, conferências ou simpósios de mútuo interesse.

Fundamentado na assinatura do Acordo entre as instituições, foi possível compartilhar as ações do Programa A3M, coordenado pelo CEAD, a partir de que foram disponibilizados parte dos projetos para serem divulgados no site da UAb, o AULAbERTA, em formato de aula aberta. No ambiente virtual da daquela universidade, pode-se ter acesso ao Programa A3M e às aulas abertas (mediante cadastro e autenticação).

No AULAbERTA, inicialmente, há uma sinopse do A3M e os objetivos do Programa: “[...] promover ações educacionais inovadoras, tendo como meta disponibilizar um portfólio sustentável de metodologias, processos e aplicativos para uso em cursos do ensino superior”. Observam-se, também, nessa apresentação, os mesmos objetivos do Programa A3M fundado em 2017 pelo CEAD, que no site consta como "Objetivos para o uso deste REP@”:

Incentivar práticas educativas inovadoras no contexto Universitário; Apoiar a pesquisa, a produção de novos conhecimentos e o desenvolvimento de metodologias educacionais inovadoras no processo de ensino e aprendizagem no ensino superior; Incentivar a cultura acadêmica para o uso das TIC como instrumento para o desenvolvimento do ensino e da aprendizagem (AULAbERTA, 2020, on-line).

A estrutura do site AULAbERTA é composta pelos seguintes itens: SINOPSE E OBJETIVOS - identificado como um “[...] Recurso Pedagógico Aberto (REP@) é parte do Projeto Millenium"; AUTORIA - "Recursos e materiais cedidos pelo Centro de Educação a Distância - CEAD/UnB, adaptados pela UAb”; CALENDÁRIO - "Recurso aberto em permanência, para exploração autónoma”; TRABALHO ESTIMADO - "A exploração dos conteúdos disponibilizados neste ReP@ tem uma duração aproximada de 3h”; PARCERIA - "A disponibilização dos recursos e informações sobre o Programa Aprendizagem para o $3^{\text {o }}$ Milênio (A3M) resulta de uma parceria entre a Universidade Aberta (UAb) e a Universidade de Brasília (UnB)”.

A internacionalização desses recursos pela UAb possibilita ao CEAD atender aos seus objetivos de extensão e internacionalização, pautando-se pela integração do ensino como 
atividade mediadora da pesquisa realizada por professores e alunos e da sua aplicação (extensão em nível internacional).

O site da UAb apresenta o ambiente desenvolvido no Brasil e os espaços de socialização dos projetos identificados pelo programa A3M. Com a socialização dessas ações, o CEAD tem o intuito de institucionalizar metodologias ativas, com o objetivo de promover mudanças na educação superior. Esses projetos são desenvolvidos com uso de várias metodologias, alguns por meio de aulas presenciais com uso de TDIC, possibilitando a abordagem híbrida de ensino.

O AULAbERTA disponibiliza dois projetos que estão no acordo entre Unb e UAb, com o título "Recurso Pedagógico Aberto (REP@) é parte do Projeto Millenium” (UAb /LISBOA, 2019), conforme descritos a seguir.

Os projetos Rei e Rainha da Derivada (RDD), Summaê e Trezentos, coordenados pelo professor Dr. Ricardo Fragelli, são compostos por metodologias de ensino e aprendizagem ativas, que favorecem o protagonismo do estudante. Objetivam a aplicação de metodologias inovadoras para potencializar o trabalho colaborativo e envolvem maior integração no relacionamento entre professores e estudantes. Essa metodologia se aplica à disciplina de cálculo, possibilitando acolhimento e melhoria da participação dos alunos, com consequente melhoria do desempenho. $\mathrm{O}$ A3M/CEAD apoia o projeto com fomento direto para a produção de recursos que possibilitam maior qualidade às experiências inovadoras aplicadas em aulas de cálculo: quadros móveis para o concurso Rei e Rainha da Derivada (RDD); redesign do site do Summaê e um aplicativo para o Método Trezentos. Mesmo idealizadas na área da Matemática, tais metodologias são passíveis de aplicação em diversas áreas do conhecimento, possibilitando a melhoria na mediação pedagógica (ensino) e na aprendizagem ativa do aluno. O projeto de internacionalização da $\mathrm{UAB} / \mathrm{UnB} / \mathrm{UAb}$, por meio da articulação de projetos dessa natureza, possibilita ampliação de metodologias ativas e o desenvolvimento da inovação educacional.

O aplicativo web Game-Libras, coordenado pelo professor Dr. Eduardo Felten, é uma ferramenta didática que possibilita melhor aprendizagem e divulgação da Língua Brasileira de Sinais na UnB. O projeto criou um aplicativo e teve como objetivo utilizá-lo para a mediação do processo de ensino e aprendizagem de Libras, com a utilização de games. Além disso, visou “ $[\ldots .$.$] oferecer material adequado com a modalidade viso-espacial da língua aos$ estudantes surdos e não-surdos matriculados nas disciplinas de LSB Básico e LSB Básico EAD, oferecidos na Universidade de Brasília (UnB)” (UnB, 2019). Ele pode ser utilizado nas diversas modalidades e níveis de ensino, possibilitando o ensino e aprendizagem, a pesquisa e 
a extensão de recursos e metodologia inclusiva e inovadora. A contribuição do CEAD, no processo extensão universitária, apresenta-se assim integrada ao ensino e à pesquisa.

Entende-se, dessa forma, que a experiência do CEAD junto à UAb atende à diretriz do Plano de Internacionalização da Universidade de Brasília (UNB, 2018, p. 20), especificamente àquela que se refere à pesquisa integrada e para a inovação:

a institucionalização das ações de cooperação internacional desenvolvidas por iniciativa de pesquisadores da UnB devem ser estimulada por meio da criação de núcleos temáticos e/ou redes internacionais, capazes de federar iniciativas de diferentes áreas do conhecimento. Trata-se de perenizar e coletivizar as cooperações e parcerias internacionais, construídas individualmente pelos pesquisadores $($ bottom- $u p)$, a fim de promover a sua institucionalização (top-down), de forma interdisciplinar.

$\mathrm{O}$ acordo UnB/UAb revela-se, por todo o descrito, uma estratégia orientada para o desenvolvimento de alternativas de compartilhamento de produção de conhecimento e de experiências institucionais inovadoras, contribuindo, assim, para o alcance das expectativas da instituição quanto à internacionalização. Nesse sentido, corrobora o entendimento de Morosini (2019), pelo qual a política de internacionalização volta-se para a sinergia entre o ensino, a pesquisa e a extensão, evidenciando as potencialidades dos países parceiros, no caso, da UAb.

As ações do CEAD também contribuem para a internacionalização da UnB no exterior (Altbach, 2009), ao projetar experiências como o AULAbERTA para além das fronteiras institucionais e nacionais. No âmbito da internacionalização em casa, o Acordo possibilita a presença da UAb nas práticas da universidade, enriquecendo a dimensão internacional na experiência do campus, por meio de estudantes (da modalidade presencial) e de professores.

Por essa via, o CEAD evidencia sua contribuição à internacionalização da UnB, no âmbito da "internacionalização no exterior", restando o desafio da "internacionalização em casa", sobretudo pela via da mobilidade acadêmica, ainda não regulamentada para estudantes de cursos a distância.

\section{Considerações finais}

Constituímos, como foco originário desta discussão, a análise de como o CEAD, no cenário organizado pelo projeto de desenvolvimento institucional da UnB, contribui para a efetivação da política de internacionalização da universidade. Foi possível constatar que isso tem se materializado - mais recente e concretamente - por um Acordo entre a UnB e a UAb, por meio do qual, até o presente, foram desenvolvidas ações de compartilhamento de produção de conhecimento e de experiências institucionais inovadoras. 
Orbitou essa problemática a preocupação acerca da aderência de tais iniciativas às finalidades essenciais de ensino, pesquisa e extensão da UnB, com foco na inovação. A análise dos documentos institucionais, bem como dos produtos parciais de tal Acordo, sinalizam positivamente nesse sentido. A relação entre a UAB e a UAb parece se projetar sobre os pilares da coparticipação, da abertura cultural e da ambiência de inovação, com vistas a complexidade das questões locais e globais. Exemplo disso se observa na construção de "Aulas Abertas" que integram a produção de conhecimentos e metodologias da UnB e o desenho tecnológico da UAb, de maneira integrada e produtiva.

Ainda a respeito do Acordo, a preocupação com a manutenção do caráter copartícipe dessa internacionalização mantém-se, contudo, latente. Não se deve afastar a hipótese de que esse tipo de processo possa produzir, em ambas as partes, limitações estruturais, subordinações ou importação racional-técnica de modelos externos, implicando em fragilização da identidade institucional e do alcance de metas de desenvolvimento particulares. Nesse sentido, é produtivo ressaltar a importância de que acordos dessa natureza se constituam sob rígida definição de forma e funcionalidade, bem como que mantenham em plena vigilância as preocupações institucionais e suas consequências organizacionais e culturais.

Por fim, cabe indicar possibilidades de expansão desta discussão, considerando que o objetivo primário deste artigo foi a panoramização do fenômeno, sem uma análise teórica mais sistemática. Para estudos futuros, sugere-se a retomada da evolução do conceito de internacionalização, com base em autores de referência da área como Hans de Wit, Jane Knight e John Hudzik, o que poderia contribuir para análises aprofundadas de ações de internacionalização, tanto na UnB quanto em outras instituições de ensino superior.

\section{Referências}

AULAbERTA (2020). Disponível em: https://aulaberta.uab.pt/blocks/catalog/detail.php?id=47. Acesso em: 20 jan 2020.

BRASIL. Constituição Federal de 1988. Disponível em: http://www.planalto.gov.br/ccivil_03/constituicao/constituicao.htm. Acesso em: 30 jul 2019.

AltbaCH. P. G.; REISBERG, L.; RUMBley, L. E. Trends in Global Higher Education: Tracking an Academic Revolution. A Report Prepared for the UNESCO 2009 World Conference on Higher Education. Paris: UNESCO, 2009.

BARDIN, L. Análise de conteúdo. São Paulo: Edições 70, 2011.

BOLL, C. I. Enunciação Estética Juvenil em Vídeos Escolares no YouTube. Tese de Doutorado. Tese de Doutorado em Educação - Faculdade de Educação. UFRGS, Porto Alegre, 2013. Disponível em: http://www.lume.ufrgs.br/handle/10183/70596. Acesso em: 10 jul 2019. 
FULLAN, M. El Cambio educativo: guía de planeación para maestros. México: Trilhas, 2000.

GASPARIN, J. L. Uma Didática para a Pedagogia histórico-crítica. Campinas: Autores Associados, 2007.

GIL. A. C. Como elaborar projetos de pesquisa. São Paulo: Atlas, 2017.

MINAYO, M. C. S. (Org.). Pesquisa social: teoria, método e criatividade. 21. ed. Petrópolis: Vozes, 2002.

MOROSINI, M. Guia para a internacionalização universitária. Porto Alegre: EDIPUCRS, 2019.

MOROSINI, M.; CORTE, M. G. D. Teses e realidades no contexto da internacionalização da educação superior no Brasil. Revista Educação em Questão, Natal, v. 56, n. 47, p. 97 120, jan./mar. 2018.

SOUSA, J. V. de. Internacionalização da Educação Superior como indicador do Sinaes: de qual qualidade estamos falando? Educação (Porto Alegre), v. 40, n. 3, p. 343-356, set.- dez. 2017.

TAKAHASHI, T. (Org.). Sociedade da informação no Brasil: livro verde. Brasília: Ministério da Ciência e Tecnologia, 2000.

UNIVERSIDADE ABERTA DE PORTUGAL. Aula Aberta. Disponível em: https://aulaberta.uab.pt/. Acesso em: 10 set 2019.

UNIVERSIDADE DE BRASÍlLIA (UnB). Acordo de Cooperação entre a UnB e a Universidade Aberta de Portugal, 2018. Brasília, DF: UNB, 2008.

UNIVERSIDADE DE BRASÍlIA (UnB). Ato da Reitoria no. 822 de 2005. Brasília, DF: $\mathrm{UNB}, 2005$.

UNIVERSIDADE DE BRASÍlLIA (UnB). Ato da Reitoria $\mathbf{n}^{\circ} 138$ de 10 de abril de 1989. Brasília, DF: UNB, 1989.

UNIVERSIDADE DE BRASÍLIA (UnB). Ato da Reitoria $\mathbf{n}^{\mathbf{0}} 291$ de 2 (dois) de agosto de 1989. Brasília, DF: UNB, 1999.

UNIVERSIDADE DE BRASÍLIA (UnB). Extensão. Brasília, DF: UNB. Disponível em: https://www.unb.br/extensao. Acesso em: 30 jul 2019.

UNIVERSIDADE DE BRASÍLIA (UnB). Plano de Desenvolvimento Institucional 20182022. Brasília, DF: UNB, 2017. Disponível em: http://www.dpo.unb.br/index. Php?option=com. Acesso em: 10 jul 2019.

UNIVERSIDADE DE BRASÍLIA (UnB). Plano de internacionalização da universidade de Brasília - 2018-2022. Brasília, DF: UNB, 2018. Disponível em: http://www.int.unb.br/br/institucional/plano-de-internacionalizacao. Acesso em: 16 nov 2019.

UNIVERSIDADE DE BRASÍLIA (UnB). Programa aprendizagem para $\mathbf{3}^{\circ}$ Milênio (A3M). Brasília, DF: UNB, Disponível em: https://www.a3m.cead.unb.br/projetos/. Acesso em: 15 set 2019.

UNIVERSIDADE DE BRASÍLIA (UnB). Resolução do Conselho Diretor $\mathbf{n}^{\mathbf{o}} 2009$ de 11 de agosto de 1989. 